\title{
Determination of 4-vinylgaiacol and 4-vinylphenol in Top- fermented Wheat Beers by Isocratic High Performance Liquid Chromatography with Ultraviolet Detector
}

\author{
Mingguang $\mathrm{Zhu}^{1}$ and Yunqian $\mathrm{Cui}^{2 *}$ \\ ${ }^{l}$ College of Bioengineering; Tianjin University of Science and Technology; P.R. - China. ${ }^{2}$ China-Germany Brewing \\ Technical Center; Shandong Provincial Key Laboratory of Microbial Engineering; Shandong Polytechnic \\ University; Jinan, Shandong, P.R. - China.
}

\begin{abstract}
This work aimed at determining 4-vinylguaiacol and 4-vinylphenol in the top-fermented wheat beers using different wavelength and the mobile phase for HPLC. Best results for isocratic elution were obtained at $260 \mathrm{~nm}$ and the mobile phase comprising methanol/ultrapure water/phosphoric acid (400/590/10, V/V). Under these conditions, the retention time of 4-vinylguaiacol and 4-vinylphenol was 25 and 27min, respectively.
\end{abstract}

Key words: 4-vinylguaiacol, 4-vinylphenol, Top-fermented wheat beers, HPLC, phenolic off-flavor

\section{INTRODUCTION}

Despite being considered undesirable and cataloged as a "phenolic off-flavor" (POF) in bottom-fermented beers (Thurston et al. 1981; Thurston et al. 1986), 4-vinylguaiacol (4VG) and 4-vinylphenol (4VP) are well-known aroma compounds found in top-fermented beers, including Belgian white beers (brewed with unmalted wheat), German Weizen beers and Rauch beers (brewed with malted wheat) (Coghe et al. 2004; Vanbeneden et al. 2006; Vanbeneden et al. 2008). Both the 4VG and 4VP have a lower sensory threshold value, which are reported to be 0.3 and $0.2 \mathrm{mg} / \mathrm{L}$, respectively (Thurston et al. 1981; BDAS Online. 2006; Vanbeneden et al. 2006). Even at trace levels, they can also produce a significant medicinal, phenolic, clove-like, smoky, or BBQ flavor in beers (Thurston et al. 1981; Thurston et al. 1986; McMurrough et al. 1996; Coghe et al. 2004; Vanbeneden et al. 2008).
Hence, they are of vital importance for the overall flavor perception in these top-fermented beers.

The 4VG and 4VP have the similar structure (Fig. 1), (Vanbeneden et al. 2006; Vanbeneden et al. 2008). Their molecular weights are 150.18 and 120.15 , respectively. The universal method to determine the 4VG and 4VP is by High Performance Liquid Chromatography (HPLC) with gradient pump (McMurrough et al. 1996, Shinohara et al. 2000; Vanbeneden et al. 2008). Nevertheless, there are also different analysis methods for different detectors. For example, for fluorescence monitor, mobile phase is $\mathrm{H}_{2} \mathrm{O} / \mathrm{CH}_{3} \mathrm{OH} / \mathrm{H}_{3} \mathrm{PO}_{4}=540: 450: 10$ and excitation and emission wavelength is $259 \mathrm{~nm}$ and $341 \mathrm{~nm}$, respectively (McMurrough et al. 1996); for U.V. detector, mobile phase is $\mathrm{H}_{2} \mathrm{O} / \mathrm{CH}_{3} \mathrm{CN} / \mathrm{H}_{3} \mathrm{PO}_{4}=599: 400: 1$ and wavelength is $230 \mathrm{~nm}$ (Shinohara et al. 2000); for electrochemical detector, mobile phase is $\mathrm{H}_{2} \mathrm{O} / \mathrm{CH}_{3} \mathrm{OH} / \mathrm{H}_{3} \mathrm{PO}_{4}=745: 245: 10$, and the working electrode is $\mathrm{Ag} / \mathrm{AgCl},+1200 \mathrm{mV}, 100 \mathrm{nA}$

*Author for correspondence: cuiyunqian@yahoo.com.cn 
(Vanbeneden et al. 2006; Vanbeneden et al. 2008), etc.

This work aimed to study the determination of $4 \mathrm{VG}$ and $4 \mathrm{VP}$ in top-fermented wheat beers by isocratic HPLC with ultraviolet detector.<smiles>C=Cc1ccc(O)c(OC)c1</smiles><smiles>C=Cc1ccc(O)cc1</smiles>

Figure 1 - The chemical structure of $4 \mathrm{VG}$ (left) and 4VP (right).

\section{EXPERIMENTAL}

\section{Reagents and materials}

HPLC grade 4VG ( $\geq 98 \%$, 2-methoxy-4vinylphenol) and 4VP (10\% in propylene glycol) were purchased from SAFC (UK) and Alfa Aesar (Tianjin, China), respectively. HPLC grade methanol and acetonitrile were obtained from Tianjin Siyou Chemical Reagent Co, Ltd (Tianjin, China) and Jinan Institute of Chemical Engineering (Jinan, Shandong, China), respectively. Phosphoric acid (85\%) was analytical grade. The ultrapure water used in this study was deionized and filtered by a Milli-Q Plus water purifying system (Bedford, MA, USA). Scarlett barley malt was procured from Zhongliang Malt Division (Dalian, China). Wheat malt was obtained from Weyermann (Bamberg, Germany). Hops were supplied from Barth-Haas Group (Beijing, China), which contained $4.9 \%$ a-acids (Analytica-EBC) (Cui et al. 2010).

\section{HPLC system}

LC-10AT HPLC (Shimadzu) and Rheodyne 7725i manual sampler were used. Absorption spectra were recorded with a UV spectrophotometer, model SPD-10Avp. Isocratic separation was performed on a reversed-phase $\mathrm{C}_{18}$ column (4.6 $\mathrm{mm} \times 150 \mathrm{~mm}, 5 \mu \mathrm{m}$ particle size, Diamonsil). The measurements were carried out at room temperature. The flow rate was at $1 \mathrm{~mL} / \mathrm{min}$. The injection volume was $20 \mu \mathrm{L}$.

\section{Preparation of 4VG and 4VP standard solutions}

According to the density of $4 \mathrm{VG}$ and $4 \mathrm{VP}$ as 1.10 and $1.04 \mathrm{mg} / \mathrm{L}$, respectively, the standard solution of $4 \mathrm{VG}$ and $4 \mathrm{VP}$ were prepared as mentioned in Table 1.

Table 1 - Preparation of $4 \mathrm{VG}$ and $4 \mathrm{VP}$ standard solution.

\begin{tabular}{|c|c|c|}
\hline & $\begin{array}{c}\text { Concentrations of } \\
\text { standard substance }\end{array}$ & $\begin{array}{c}\text { Preparation } \\
\text { methods }\end{array}$ \\
\hline $4 \mathrm{VG}$ & $\begin{array}{l}15 \mu \mathrm{L} \times 1.10 \mathrm{~g} / \mathrm{mL} \div \\
250 \mathrm{~mL}=66 \mathrm{mg} / \mathrm{L}\end{array}$ & $\begin{array}{l}15 \mu \mathrm{L} \text { standard } \\
\text { substance }+149.985 \\
\mathrm{~mL} \text { mobile phase }\end{array}$ \\
\hline $4 \mathrm{VP}$ & $\begin{array}{l}300 \mu \mathrm{L} \times 1.04 \mathrm{~g} / \mathrm{mL} \times 10 \% \\
\div 50 \mathrm{~mL}=624 \mathrm{mg} / \mathrm{L}\end{array}$ & $\begin{array}{l}300 \mu \mathrm{L} \text { standard } \\
\text { substance }+49.700 \\
\mathrm{~mL} \text { mobile phase }\end{array}$ \\
\hline
\end{tabular}

\section{Preparation of samples}

The top-fermented wheat beers were fermented in the pilot-scale brewery $(20 \mathrm{hL})$ in Shandong Polytechnic University. Brewing process was carried out as follows. barley malt $(102 \mathrm{~kg})$, wheat malt $(68 \mathrm{~kg})$, brewing water $(5.95 \mathrm{hL})$, mashing procedure: $44^{\circ} \mathrm{C}(20 \mathrm{~min}), 52^{\circ} \mathrm{C}(40 \mathrm{~min}), 65^{\circ} \mathrm{C}$ (70 $\mathrm{min}), 72^{\circ} \mathrm{C}(15 \mathrm{~min}), 78^{\circ} \mathrm{C}(10 \mathrm{~min})$, wort lautering by lauter tun, boiling for $90 \mathrm{~min}$ in wort kettle, wort clarification in whirlpool, original gravity is $11^{\circ} \mathrm{P}$, fermentation temperature $20^{\circ} \mathrm{C}(5$ days), lagering period 7 days at $0^{\circ} \mathrm{C}$ (Cui et al. 2010).

Mobile phases and samples were filtered through $0.45 \mu \mathrm{m}$ pore PVDF membrane filters and then decarbonated by sonication. All the samples were protected from light during operation to minimize the photo-isomerisation reaction.

\section{The determination of the optimized absorption wavelength}

Wavelength ranges were set between 190-300 nm on the ultraviolet spectrophotometer to confirm the optimal absorption wavelength.

The determination of the optimal mobile phase The 4VG and 4VP standard solutions were mixed at the rate of 1:1. The mobile phases consisted of acetonitrile/ultrapure water/phosphate and methanol/ultrapure water/phosphoric acid as shown in Table 2.

Table 2- Different mobile phase used in the study.

\begin{tabular}{cl}
\hline No. & \multicolumn{1}{c}{ Mobile phase } \\
\hline A & $\begin{array}{l}\text { Acetonitrile/ultrapure water/phosphoric acid } \\
=300 / 690 / 10\end{array}$ \\
B & $\begin{array}{l}\text { Acetonitrile/ultrapure water/phosphoric acid } \\
=200 / 790 / 10\end{array}$ \\
C & $\begin{array}{l}\text { Methanol/ultrapure water/phosphoric acid } \\
=400 / 590 / 10\end{array}$ \\
D & $\begin{array}{l}\text { Methanol/ultrapure water/phosphoric acid } \\
=600 / 390 / 10\end{array}$ \\
\hline
\end{tabular}


The determination of 4VG and 4VP concentrations in top-fermented wheat beers The top-fermented wheat beers were injected into HPLC under the conditions of optimized absorption wavelength and mobile phase in this study so as to determine the levels of $4 \mathrm{VG}$ and 4VP.

\section{RESULTS AND DISCUSSION}

\section{The determination of the optimum absorption} wavelength

The wavelength (190 300 nm) scanning maps of 4VG and 4VP are shown in Figure 2, respectively. There was a relatively better absorption peak at $260 \mathrm{~nm}$ for both the 4VG and 4VP. Furthermore, according to the proper property of acetonitrile and methanol, the absorption values of them were less than 0.005 and 0.01 at $260 \mathrm{~nm}$, respectively. Hence, it was an appropriate choice to set the wavelength at $260 \mathrm{~nm}$ to separate the $4 \mathrm{VG}$ and 4VP entirely.

The determination of the optimal mobile phase The 4VG and 4VP standard solutions were mixed at the rate of 1:1 and their standard solutions with different mobile phases shown in Table 2 were injected into HPLC system. The corresponding spectra are shown in Figure 3.

Figure $3 \mathrm{C}$ showed that the peaks of $4 \mathrm{VG}$ and $4 \mathrm{VP}$ could be separated completely and the analysis time was the shortest, so the optimal mobile phase was methanol/ultrapure water/phosphoric acid $(400 / 590 / 10, \mathrm{~V} / \mathrm{V})$ and the analysis time of 4VP and $4 \mathrm{VG}$ was about 25 and $27 \mathrm{~min}$, respectively.
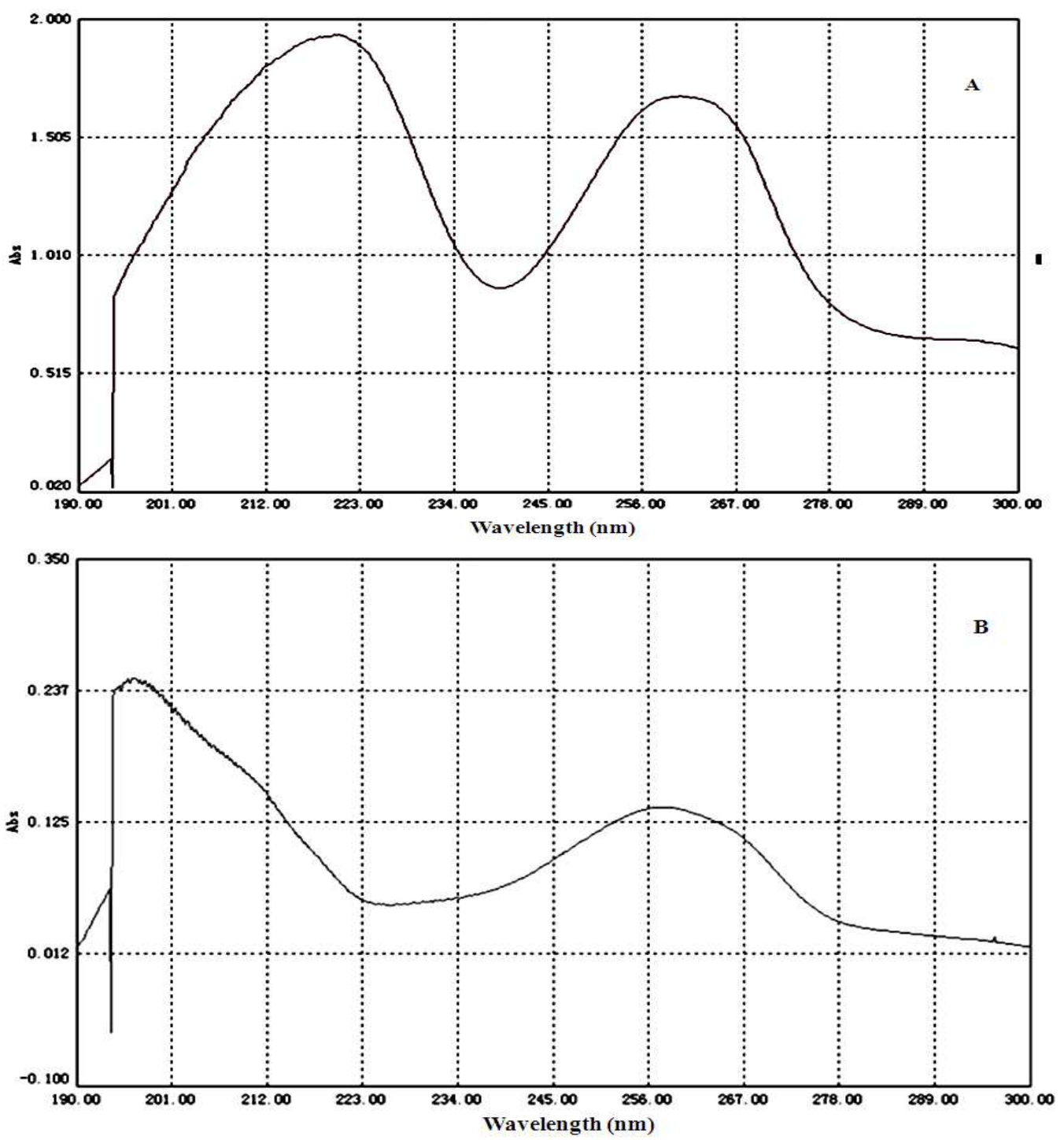

Figure 2 - The wavelength scanning maps of $4 \mathrm{VG}(\mathrm{A})$ and $4 \mathrm{VP}(\mathrm{B})$. 

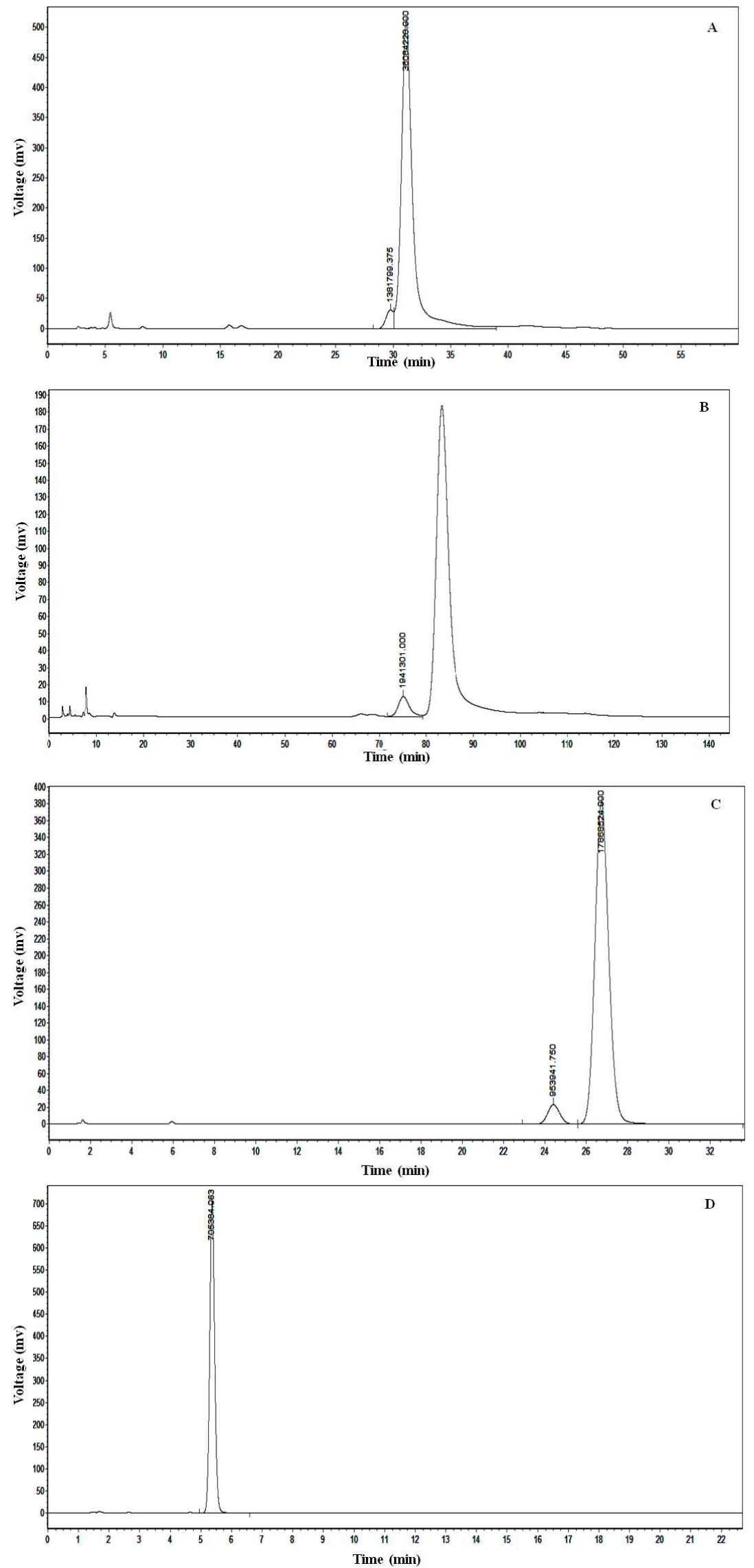

Figure 3 - Standard solution spectra eluted with different mobile phase (No. A-D in Table 2). 
The drawing of $4 \mathrm{VG}$ and $4 \mathrm{VP}$ standard curves The five concentration gradients of $4 \mathrm{VG}$ or $4 \mathrm{VP}$ were prepared and injected into HPLC according to standard operations. Peak areas were obtained as shown in Table 3. Consequently, standard curves of $4 \mathrm{VG}$ and $4 \mathrm{VP}$ were drawn (Fig. 4).

Table 3 - Concentrations and peak areas of $4 \mathrm{VG}$ and 4VP.

\begin{tabular}{lccccc}
\hline & $\mathbf{1}$ & $\mathbf{2}$ & $\mathbf{3}$ & $\mathbf{4}$ & $\mathbf{5}$ \\
\hline 4VG & 1.110 & 2.220 & 2.960 & 4.440 & 5.550 \\
concentration & 11.928 & 90.100 & 12.8940 & 19.7724 & 22.7081 \\
4VG peak area & 62.42 & & \\
4VP & 0.416 & 0.832 & 1.248 & 1.664 & 2.080 \\
concentration & 16.407 & 28.802 & 46.814 & 63.817 & 78.743 \\
\hline 4VP peak area & 16.04
\end{tabular}

\section{Determination of $4 \mathrm{VG}$ and $4 \mathrm{VP}$ concentrations in top-fermented wheat beers}

The top-fermented wheat beers were injected into HPLC under the conditions of optimized absorption wavelength and mobile phase. The, spectrum of top-fermented wheat beers and closeup spectrum of $4 \mathrm{VG}$ and $4 \mathrm{VP}$ are shown in Figures 5 and 6, respectively.

The $4 \mathrm{VG}$ and $4 \mathrm{VP}$ peaks in Figure 6 were substituted in the standard curve equations of $4 \mathrm{VG}$ and 4VP in Figure 4. After calculation, the contents of $4 \mathrm{VG}$ and $4 \mathrm{VP}$ in the top-fermented wheat beers found were 2.6133 and $1.0095 \mathrm{mg} / \mathrm{L}$, respectively, which was similar to the findings of Wackerbauer et al. (1982) and Schwarz et al. (2012).
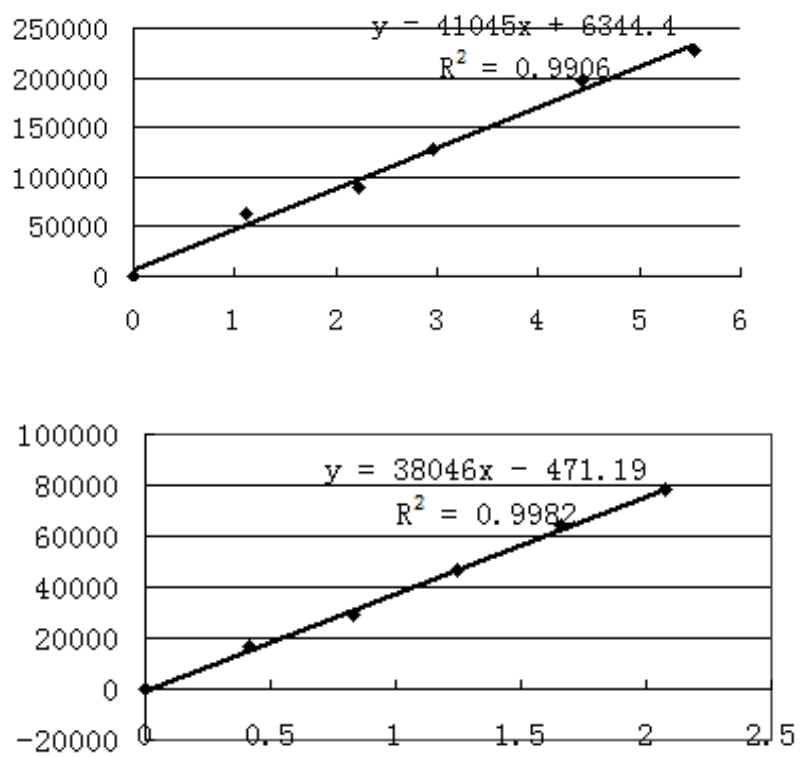

Figure 4 - Standard curves of 4VG (left) and 4VP (right).

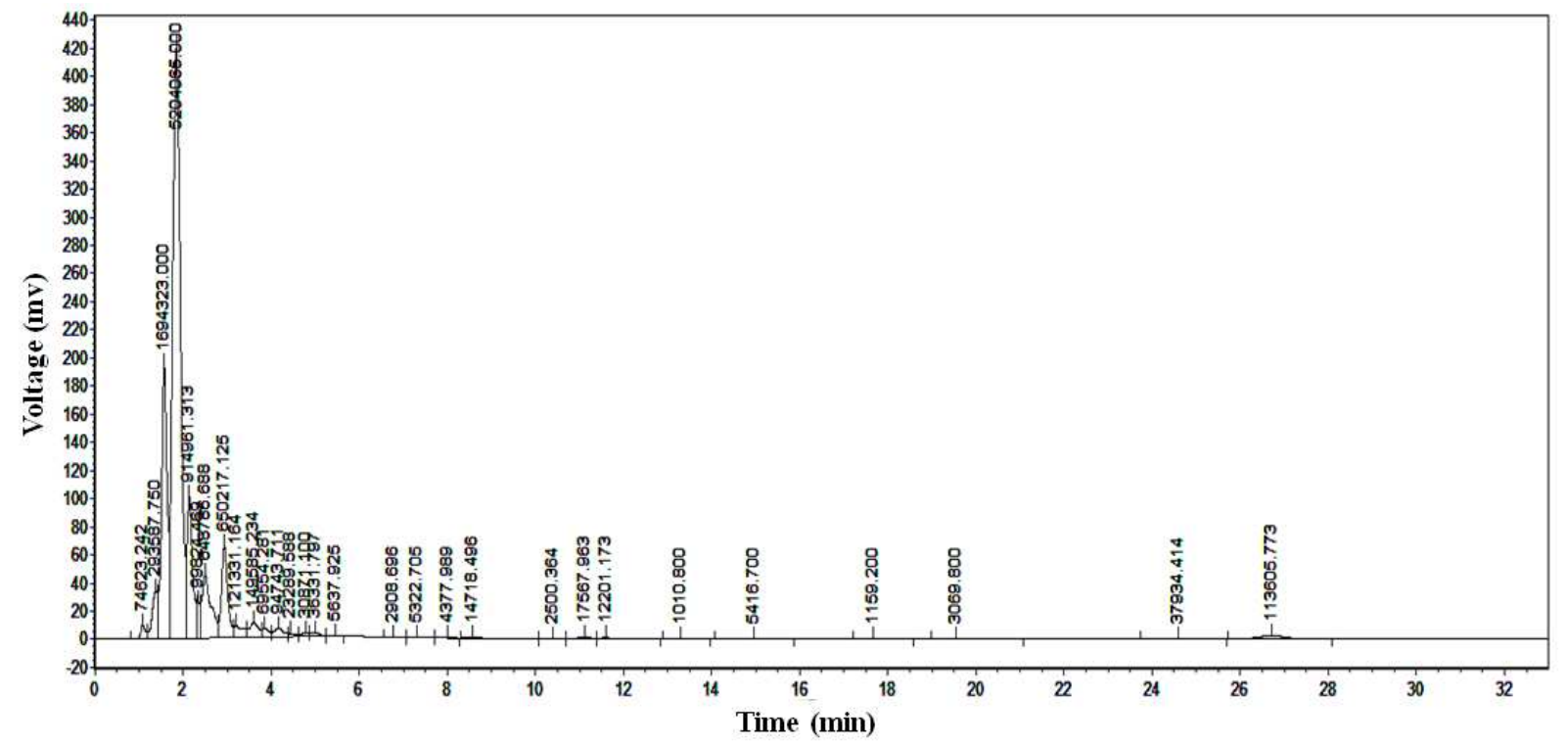

Figure 5 - Spectrum of top-fermented wheat beers. 


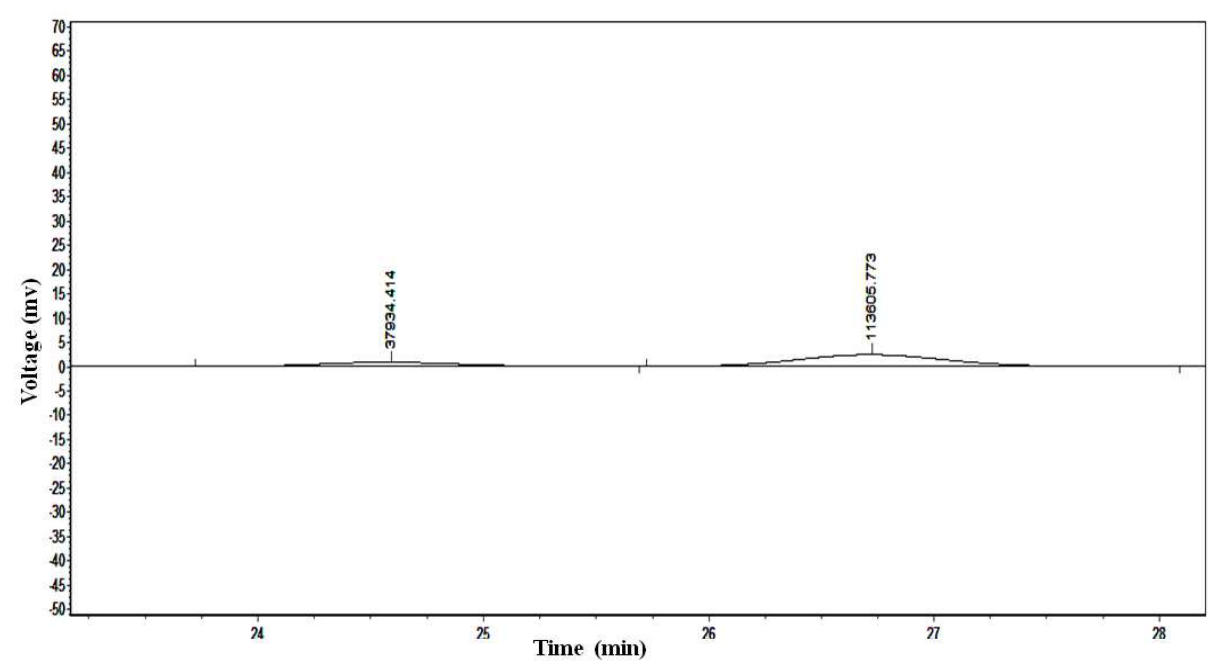

Figure 6 - Close-up spectrum of 4VG (right) and 4VP (left).

\section{CONCLUSION}

In summary, under the existing conditions (LC10AT, 7725i manual sampler, SPD-10Avp UV spectrophotometer, reversed-phase $\mathrm{C}_{18}$ column), the optimum HPLC conditions were wavelength at $260 \mathrm{~nm}$, the mobile phase methanol/ultrapure water/phosphoric acid (400/590/10, V/V), flow rate $1.0 \mathrm{~mL} / \mathrm{min}$ and injection volume $20 \mu \mathrm{L}$. This resulted the analysis time of the $4 \mathrm{VP}$ and $4 \mathrm{VG}$ as 25 and $27 \mathrm{~min}$, respectively.

\section{ACKNOWLEDGMENTS}

We thank Weiyue Zhu (Shandong Polytechnic University) for constant support and guidance in HPLC operation.

\section{REFERENCES}

BDAS Online [homepage on the internet]. Kentucky USA: Brewing and Distilling Analytical Services, LLC, c2003-2013 [cited 2006 Oct. 10]. Available from: http://www.alcbevtesting.com/testingfacilities/flavor-corner.

Coghe S, Benoot K., Delvaux F, Vanderhaegen B, Delvaux FR. Ferulic Acid Release and 4Vinylguaiacol Formation during Brewing and Fermentation: Indications for feruloyl esterase activity in Saccharomyces cerevisiae. J Agric Food Chem. 2004; 52(3): 602-608.

Cui YQ, Cao XH, Li SS, Thamm L, Zhou GT. Enhancing the concentration of 4-vinylguaiacol in top-fermented beers-a review. J Am Soc Brew Chem. 2010; 68(2):77-82.

McMurrough I, Madigan D, Donnelly D, Hurley J, Doyle AM, Hennigan G, et al. Control of ferulic acid and 4-vinyl guaiacol in brewing. J Inst Brew. 1996; 102:327-332.

Schwarz KJ, Stübner R, Methner FJ. Formation of styrene dependent on fermentation management during wheat beer production. Food Chem. 2012; 134 (4):2121-2125.

Shinohara T, Kubodera S, Yanagida F. Distribution of phenolic yeasts and production of phenolic offflavours in wine fermentation. J Biosci Bioeng. 2000; 90 (1):90-97.

Thurston PA. The phenolic off-fllavor test: a method for confirming the presence of wild yeasts. J Inst Brew. 1986; 92: 9-10.

Thurston PA, Tubb RS. Screening yeast strains for their ability to produce phenolic off-flavours: A simple method for determining phenols in wort and beer. $J$ Inst Brew. 1981; 87: 177-179.

Vanbeneden N, Delvaux F, Delvaux FR. Determination of hydroxycinnamic acids and volatile phenols in wort and beer by isocratic high-performance liquid chromatography using electrochemical detection. $J$ Chromatogr A. 2006, 1136 (2):237-242.

Vanbeneden N, Gils F, Delvaux F, Delvaux FR. Formation of 4-vinyl and 4-ethyl derivatives from hydroxycinnamic acids: Occurrence of volatile phenolic flavour compounds in beer and distribution of Pad1-activity among brewing yeasts. Food Chem. 2008; 107 (1):221-230.

Wackerbauer K, Kramer P. Bavarian wheat beer - an alternative production and composition. Brauwelt. 1982; 122 (18):758-762. 